\title{
Emergency medicine residency programs in Brazil:
}

\author{
a national survey
}

Henrique Herpich ${ }^{1^{*}}$, Nayara Monteiro Pinhero ${ }^{2}$ MD, Marcio da Silveira Rodrigues ${ }^{2}$ MD, Ian Ward Abdalla Maia ${ }^{3}$ MD, Lucas Oliveira J. e Silva ${ }^{4}$ MD.

\begin{abstract}
${ }^{1}$ School of Medicine, Federal University of Health Sciences of Porto Alegre (UFCSPA), Porto Alegre, RS, Brazil.
${ }^{2}$ Department of Emergency Medicine, Hospital de Clínicas de Porto Alegre, Porto Alegre, RS, Brazil.

${ }^{3}$ Department of Emergency Medicine, Hospital das Clínicas da Faculdade de Medicina da Universidade de São Paulo, São

Paulo, SP, Brazil.

${ }^{4}$ Department of Emergency Medicine, Mayo Clinic, Rochester, MN, United States.

* Corresponding author. E-mail address: herpichhenrique@gmail.com
\end{abstract}

\begin{abstract}
Study objective: To describe the characteristics and curricula of Brazilian Emergency Medicine (EM) residency programs. Methods: This was a national cross-sectional survey conducted between January and May 2021. A survey was distributed to residency directors with queries about the characteristics of their programs. Descriptive analysis was performed stratified by Brazilian regions. Results: There were a total of 35 responses from the 39 (response rate $=89.7 \%$ ) EM residency training programs in Brazil. Twelve (34.3\%) programs were in the South region, $17(48.6 \%)$ in the Southeast, $3(8.6 \%)$ in the CentralWest, and $3(8.6 \%)$ in the Northeast. These 35 programs represented a total of 166 residency slots offered per year (median 4, range 2-24). All programs are of 3-year duration. Seventeen programs (48.6\%) were officially launched in either 2019 or 2020 . The estimated proportion of faculty with prior EM residency or board certification in EM was reported to be less than $20 \%$ in 26 of 35 (74.3\%) programs. Only 5 rotations were mandatory across all 35 programs, including rotations in the emergency department (ED) intermediate acuity unit ("yellow" room), ED high acuity unit ("red" room), intensive care unit (ICU), obstetrics and gynecology, and trauma. Other rotations were highly heterogeneous across regions. Conclusion: Emergency medicine residency is clearly growing in Brazil, and there is a relatively high level of heterogeneity across programs. There is a clear need for standardization of residency curriculum.
\end{abstract}

Keywords: EM Residency, Emergency Medicine Training, Brazilian Emergency Medicine.

\section{Introduction}

Emergency Medicine (EM) is a relatively new medical specialty in most countries in the world. Its recognition occurred in the end of the 20th century in the United States, ${ }^{1}$ but several other countries have yet to formally accept and introduce EM into their healthcare systems. ${ }^{2-4}$ An important step in the process of EM development is the implementation of formal medical residency programs during which physicians get specialized training on how to provide care for undifferentiated patients of all ages at any time. The training of this new specialist - the emergency physician - is among the first steps in a chain of events that can ultimately improve the quality of emergency care systems. ${ }^{4}$ Residency programs are responsible for this training, and they need to assure that a trained emergency physician has the necessary skills and competencies to practice EM independently. ${ }^{5}$ Also, programs need to ensure that the physician will meet the needs of their healthcare systems. ${ }^{2,5}$

In Brazil, EM was officially recognized as a medical specialty between the years of 2015 and 2016. ${ }^{6}$ Before that, Brazil had two programs that pioneered the establishment of EM, one in the South 
(created in 1996) and one in the Northeast (created in 2008). ${ }^{6,7}$ Following the official establishment of the specialty in 2016, several new residency programs were launched. However, little is known about key characteristics of Brazilian EM residency programs and how standardized their training are. Brazil is among the largest countries in the world, and its internal heterogeneity can result in different training standards across its 27 federative units. There is a need to understand medical education patterns across the nation's programs to increase the probability of having a standardized curricula for future emergency physicians.

To our knowledge, no previous studies have systematically evaluated the current state of EM residencies in Brazil. In this nation-wide survey-based study, our objective was to describe the overall characteristics and curricula of Brazilian EM residency programs.

\section{Methods}

\section{Study design and population}

This was a national cross-sectional survey study conducted between January and May 2021. The study was approved by the institutional review board at Hospital de Clínicas de Porto Alegre (CAAE number 40969820.3.0000.5327).

The target population were EM residency programs in Brazil. As of January 2021, there were 46 residency programs approved by the Ministry of Education of the Brazilian Government. (Full list in Appendix S1) During the execution of this study, we found that 7 programs were still inactive despite approval by the government, yielding 39 active residency programs in the country during the study period. All 39 active programs were contacted and surveyed. The programs were considered inactive after contacting the affiliated hospitals by telephone and verifying that there was no EM program currently running.

\section{Survey development}

The survey was created to acquire information on the overall characteristics of Brazilian EM residency programs. To ensure content validity, four board-certified emergency physicians reviewed each survey question. The survey consisted of dichotomous, Likert-type, and open-ended questions. It was initially pilot tested on two program directors and five residents who provided feedback and refined its questions. Key survey domains included the following: application process and residency slots, faculty and affiliated hospitals, educational curriculum, research curriculum, and mandatory clinical rotations. To reduce the possibility of missing data, all survey questions were designed such that each item had to be answered completely before moving on to the next item. Importantly, this electronic survey was designed to be answered by program directors and EM residents, with different prompts based on their role. In this manuscript, we report data obtained through program directors as the goal was to describe the training resources and curricula of EM residency programs in Brazil. Data provided by EM residents will be reported in a separate manuscript.

\section{Sampling and survey administration}

The survey was distributed via WhatsApp groups in which EM residents and program directors were part of, via e-mail to all members of the Brazilian Association of Emergency Medicine (ABRAMEDE) and via ABRAMEDE's social media platforms (Instagram, Facebook, and Twitter). The goal was to have at least one response per program, ideally through program directors. The survey propagation message contained a brief introduction about the project and the link to the electronic survey, which was hosted at QuestionPro.com. Residency programs that were on the initial 39-program list but had not yet responded 2 weeks prior to the survey closing were identified and reached by phone and emailed at least 2 times. When more than one director responded to the survey per program, we used the responses provided by the program director who had more years in the program's leadership. Only 4 programs had more than one response.

\section{Analysis}

A descriptive analysis was performed using BlueSky Statistics (Version 7.0.746.34007) GUI for R. Continuous features were summarized as medians and ranges (minimum, maximum) or means and standard deviations (SD), as appropriate based on data distribution. Categorical features were summarized as counts and percentages. All analyses were stratified by Brazilian regions including South, Southeast, Central-West, and Northeast according to the Brazilian Institute of Geography and Statistics. To the date of the writing of this manuscript, there were no programs available in the North region.

\section{Results}




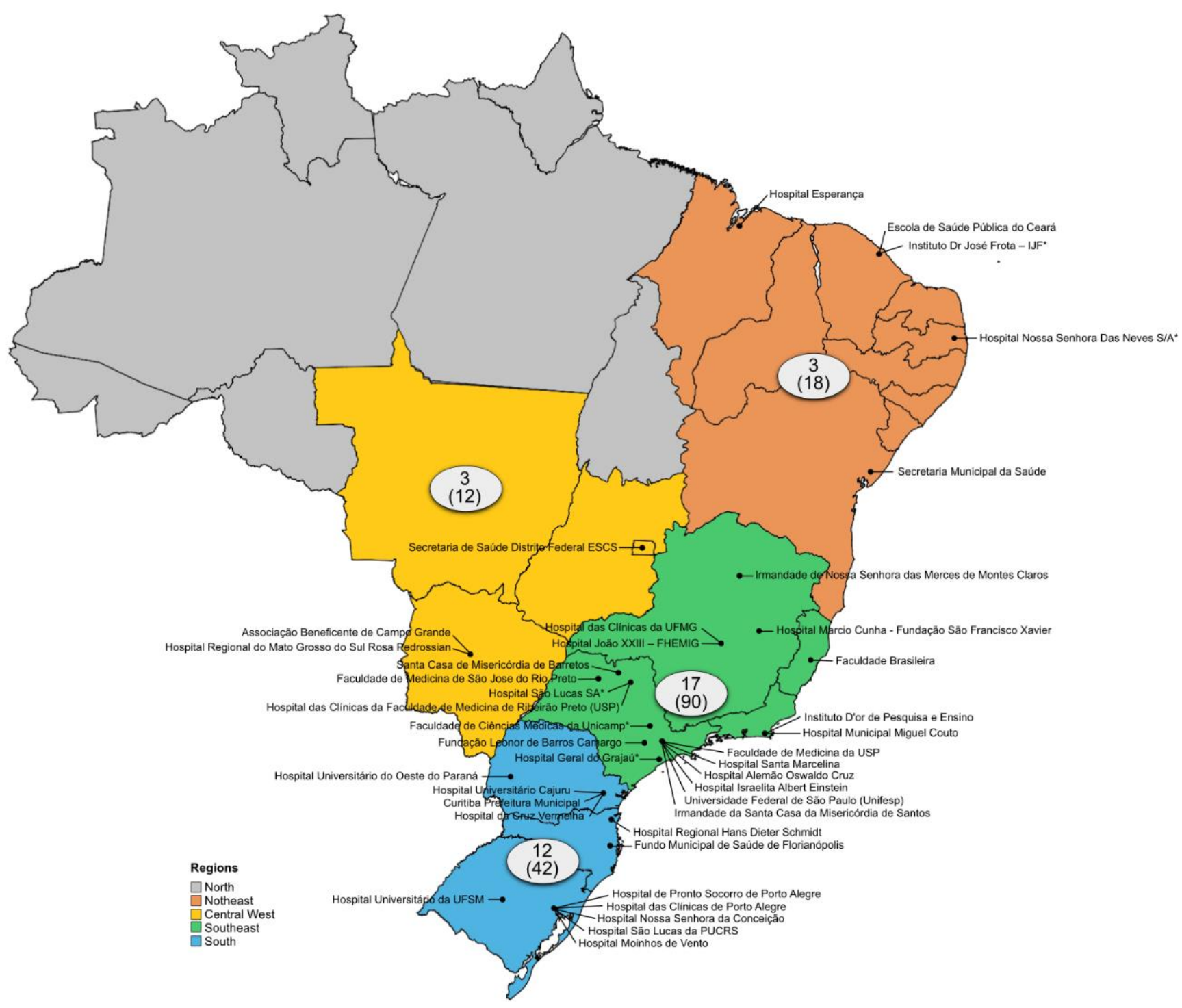

Figure 1. Geographical distribution of Brazilian EM residency programs.

Number of programs are represented per region as well as spots offered per year (in parentheses). Number of spots was based on the 2020 academic year. The asterisk $\left(^{*}\right)$ represents non-responders $(2$ in Southeast and 2 in Northeast). The seven inactive programs during the study period are not represented in this map.

There were a total of 35 responses from the 39 (response rate $=89.7 \%$ ) $\mathrm{EM}$ residency training programs in Brazil. Twelve (34.3\%) programs were in the South region, $17(48.6 \%)$ in the Southeast, 3 $(8.6 \%)$ in the Central-West, and $3(8.6 \%)$ in the Northeast. (Figure 1) These 35 programs represented a total of 166 residency slots offered per year (median 4 , range 2-24). All programs are of 3-year duration. Seventeen programs $(48.6 \%)$ were officially launched in either 2019 or 2020. Figure 2 shows the growth and development of Brazilian residency programs in EM from 1995 through 2020.

\section{Application process and residency slots}

All programs reported having a qualifying exam as part of their application process. A total of 22 $(62.9 \%)$ reported using the evaluation of curriculum vitae (CV) in their selection process, a proportion that was similar across regions except for the Northeast where only 1 out of $3(33.3 \%)$ programs reported analyzing the $\mathrm{CV}$ of their applicants. Interviews were reported to be used in 12 (34.3\%) programs and none of the Central-West and Northeast programs reported using such methods. Only four programs (11.4\%), 3 in the Southeast and 1 in the Northeast, reported that they offer more than 6 residency slots per year. The program that reported the highest number is in Sao Paulo and it offers 24 slots per year. (Table 1)

\section{Faculty and affiliated hospitals}

The median age of program directors who provided data for each program was 42 years (range $30-65)$. Only 10 (28.6\%) were female. Most directors self-reported as White $(29 / 35,82.9 \%)$, and there were 
40

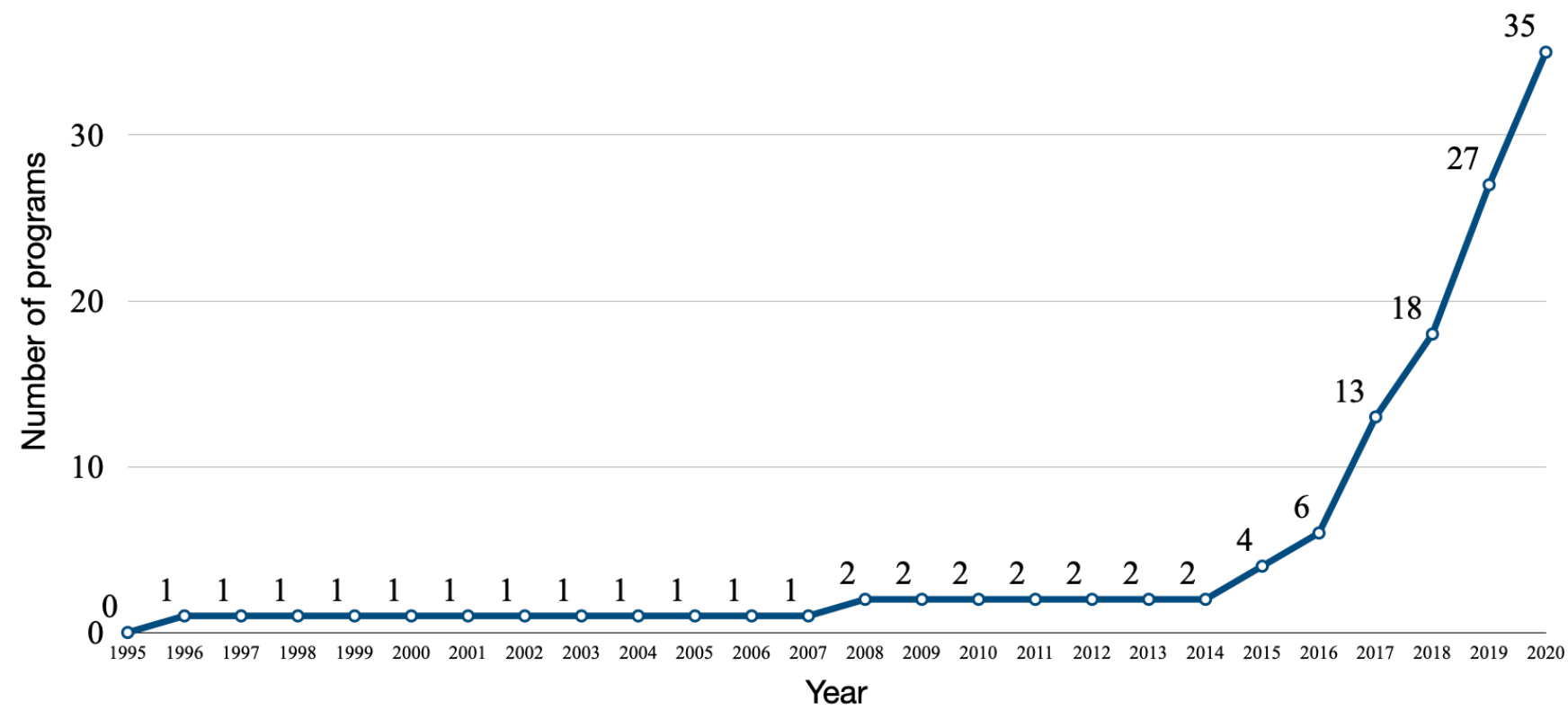

Figure 2. Growth and development of Brazilian EM residency programs between 1995 and 2020.

This graph does not include the 4 programs that did not respond to our survey (year of start not available).

only $5(14.3 \%)$ Pardos, and only $1(2.8 \%)$ Black. A total of $21(60.0 \%)$ were board-certified in EM, and 8 (22.9\%) had completed an EM residency prior to becoming program director.

The estimated proportion of faculty with prior EM residency or board certification in EM was reported to be less than $20 \%$ in 26 of $35(74.3 \%)$ programs. Only 4 programs reported having more than $80 \%$ of faculty with prior EM residency or board certification. Twenty programs $(57.1 \%$ of total) had more than 3 affiliated hospitals and 1 program reported having only 1 affiliated hospital. (Table 1 )

\section{Educational curriculum}

All but 1 program $(34 / 35,97.1 \%)$ reported having weekly lectures for residents. A total of 28 $(80.0 \%)$ reported having at least one teaching activity involving simulation per year. Monthly simulation activity was reported by 13 programs (37.1\%). Only 7 programs, being 2 in the South, 2 in the Southeast, 2 in the Central-West and 1 in the Northeast, reported having simulation activities every week. (Table 2)

\section{Research curriculum}

Research curriculum for EM residents was nationally sparse. Five programs (14.3\%) reported having no research curriculum or support for research projects. While the South region had the highest proportion $(75 \%)$ of programs with a mandatory research project before residency conclusion, the Southeast region had the highest proportion of programs with research groups/divisions available for supporting residents in their projects. Also, the Southeast and Central-West region had the highest proportion of programs in which a journal club was part of the curriculum $(64.7 \%$ and $66.7 \%$ of programs, respectively). (Table 2 )

\section{Mandatory clinical rotations}

Only 5 rotations were mandatory across all 35 programs (i.e., $100 \%$ of adherence), including rotations in the ED intermediate acuity unit ("yellow" room), ED high acuity unit ("red" room), intensive care unit (ICU), obstetrics and gynecology, and trauma. The presence of several rotations was highly heterogeneous across the different regions, including toxicology, for example, which was present in only 1 program $(8.3 \%$ of 12$)$ in the South while was reported as mandatory in all $3(100.0 \%)$ programs of the Central-West.

Rotations in the pre-hospital setting were available in all programs except for 2 programs in the South. Interestingly, despite being part of the Brazilian emergency care system, only 25 (71.4\%) programs had a mandatory rotation in emergency care units (In Portuguese, Unidades de Pronto Atendimento [UPAs]), and 31 (88.6\%) reported having a rotation in low acuity units (also known as "green" rooms in Brazilian EDs). Rotations in higher acuity and more complex settings (e.g., ICU) were mandatory in all programs. (Table 2) 
Table 1. Main characteristics of Brazilian EM residency programs.

\begin{tabular}{|c|c|c|c|c|c|}
\hline & $\begin{array}{c}\text { Total } \\
(\mathrm{N}=35)\end{array}$ & $\begin{array}{l}\text { South } \\
(N=12)\end{array}$ & $\begin{array}{l}\text { Southeast } \\
(N=17)\end{array}$ & $\begin{array}{l}\text { Central West } \\
(\mathrm{N}=3)\end{array}$ & $\begin{array}{l}\text { Northeast } \\
\qquad(\mathrm{N}=3)\end{array}$ \\
\hline \multicolumn{6}{|c|}{ Elements of application process } \\
\hline Qualifying Exam & $35(100.0 \%)$ & $12(100.0 \%)$ & $17(100.0 \%)$ & $3(100.0 \%)$ & $3(100.0 \%)$ \\
\hline CV Analysis & $22(62.9 \%)$ & $8(66.7 \%)$ & $11(64.7 \%)$ & $2(66.7 \%)$ & $1(33.3 \%)$ \\
\hline Interview & $12(34.3 \%)$ & $3(25.0 \%)$ & $9(52.9 \%)$ & $0(0.0 \%)$ & $0(0.0 \%)$ \\
\hline \multicolumn{6}{|c|}{ Number of available residency slots per year } \\
\hline 1 to 2 & $13(37.1 \%)$ & $5(41.7 \%)$ & $7(41.2 \%)$ & $0(0.0 \%)$ & $1(33.3 \%)$ \\
\hline 3 to 4 & $9(25.7 \%)$ & $4(33.3 \%)$ & $3(17.6 \%)$ & $2(66.7 \%)$ & $0(0.0 \%)$ \\
\hline 5 to 6 & $9(25.7 \%)$ & $3(25.0 \%)$ & $4(23.5 \%)$ & $1(33.3 \%)$ & $1(33.3 \%)$ \\
\hline$>6$ & $4(11.4 \%)$ & $0(0.0 \%)$ & $3(17.6 \%)$ & $0(0.0 \%)$ & $1(33.3 \%)$ \\
\hline \multicolumn{6}{|c|}{ Number of affiliated hospitals } \\
\hline 1 & $1(2.9 \%)$ & $0(0.0 \%)$ & $1(5.9 \%)$ & $0(0.0 \%)$ & $0(0.0 \%)$ \\
\hline 2 & $5(14.3 \%)$ & $1(8.3 \%)$ & $1(5.9 \%)$ & $2(66.7 \%)$ & $1(33.3 \%)$ \\
\hline 3 & $9(25.7 \%)$ & $1(8.3 \%)$ & $8(47.1 \%)$ & $0(0.0 \%)$ & $0(0.0 \%)$ \\
\hline$>3$ & $20(57.1 \%)$ & $10(83.3 \%)$ & $7(41.2 \%)$ & $1(33.3 \%)$ & $2(66.7 \%)$ \\
\hline \multicolumn{6}{|c|}{ Estimated proportion of faculty with prior EM residency or EM board certification } \\
\hline$<20 \%$ & $26(74.3 \%)$ & $8(66.7 \%)$ & $14(82.4 \%)$ & $3(100.0 \%)$ & $1(33.3 \%)$ \\
\hline $20 \%$ to $40 \%$ & $3(8.6 \%)$ & $1(8.3 \%)$ & $1(5.9 \%)$ & $0(0.0 \%)$ & $1(33.3 \%)$ \\
\hline $41 \%$ to $60 \%$ & $2(5.7 \%)$ & $1(8.3 \%)$ & $1(5.9 \%)$ & $0(0.0 \%)$ & $0(0.0 \%)$ \\
\hline $61 \%$ to $80 \%$ & $0(0.0 \%)$ & $0(0.0 \%)$ & $0(0.0 \%)$ & $0(0.0 \%)$ & 0 (0.0\%) \\
\hline$>80 \%$ & $4(11.4 \%)$ & $2(16.7 \%)$ & $1(5.9 \%)$ & $0(0.0 \%)$ & 1 (33.3\%) \\
\hline
\end{tabular}

Point-of-care ultrasound (POCUS) rotations, an area of great interest and importance in EM, were reported to be mandatory in $24(68.6 \%)$ programs, with proportions very similar across the different regions $(66.7 \%$ of programs in the South, $70.6 \%$ in the Southeast, $66.7 \%$ in the Central-West, and $66.7 \%$ in the Northeast).

\section{Discussion}

Brazil has made important strides in the development of EM within the last decade. Approximately half of the current EM residency training programs were launched in the past 2 years, representing an important step towards the widespread adoption of the specialty. Although the national growth of EM is clear, there is remarkable heterogeneity across the country regarding training availability and resources. Most EM residency programs are concentrated in the Southeast and South regions, without a national uniformity and with apparent disparities. The uneven distribution of programs across the country can be partially explained by some known factors related to the history of EM in Brazil and to the country's sociodemographic characteristics. For example, if we calculate the number of programs per million of people in each region, the South has the highest number of EM programs per capita, which is partly explained by the fact that the first EM residency program started in this region back in 1996. Besides that, the South has among the highest GDP per capita in Brazil. ${ }^{8}$ On the other hand, despite being a pioneer in the specialty and the second most populous region in the country with approximately 56 million people, the Northeast has only 3 programs available. This likely speaks to the fact that the Northeast has the lowest GDP per capita when compared to other Brazilian regions. ${ }^{8}$

Most EM residency programs in Brazil have stated that less than $20 \%$ of faculty have had board certification in EM or prior EM residency, which is compatible with the recent recognition of the specialty. Unfortunately, this data reflects that Brazilian EDs are filled by non-emergency physicians. If places with residency programs have such low proportions of EM trained physicians, hospitals without a program available likely have even lower representation. Since the start of EM board certification in 2017 and up to 
Table 1. Main characteristics of Brazilian EM residency programs.

\begin{tabular}{|c|c|c|c|c|c|}
\hline & $\begin{array}{c}\text { Total } \\
(\mathrm{N}=35)\end{array}$ & $\begin{array}{l}\text { South } \\
(N=12)\end{array}$ & $\begin{array}{l}\text { Southeast } \\
(N=17)\end{array}$ & $\begin{array}{l}\text { Central West } \\
(\mathrm{N}=3)\end{array}$ & $\begin{array}{l}\text { Northeast } \\
(\mathrm{N}=3)\end{array}$ \\
\hline \multicolumn{6}{|l|}{ Teaching curriculum } \\
\hline Weekly lectures & $34(97.1 \%)$ & $12(100.0 \%)$ & $16(94.1 \%)$ & $3(100.0 \%)$ & $3(100.0 \%)$ \\
\hline Any simulation activities & $28(80.0 \%)$ & $8(66.7 \%)$ & $15(88.2 \%)$ & $3(100.0 \%)$ & $2(66.7 \%)$ \\
\hline Weekly simulation & $7(20.0 \%)$ & $2(16.7 \%)$ & $2(11.8 \%)$ & $2(66.7 \%)$ & $1(33.3 \%)$ \\
\hline Monthly simulation & $13(37.1 \%)$ & $5(41.7 \%)$ & $6(35.3 \%)$ & $1(33.3 \%)$ & $1(33.3 \%)$ \\
\hline Biannual simulation & $6(17.1 \%)$ & $1(8.3 \%)$ & $5(29.4 \%)$ & $0(0.0 \%)$ & $0(0.0 \%)$ \\
\hline Annual simulation & $2(5.7 \%)$ & $0(0.0 \%)$ & $2(11.8 \%)$ & $0(0.0 \%)$ & $0(0.0 \%)$ \\
\hline \multicolumn{6}{|l|}{ Research curriculum } \\
\hline $\begin{array}{l}\text { Research groups } \\
\text { available for support }\end{array}$ & $11(31.4 \%)$ & $3(25.0 \%)$ & $7(41.2 \%)$ & $0(0.0 \%)$ & $1(33.3 \%)$ \\
\hline $\begin{array}{r}\text { Mandatory research } \\
\text { project for residency } \\
\text { conclusion }\end{array}$ & $20(57.1 \%)$ & $9(75.0 \%)$ & $7(41.2 \%)$ & $2(66.7 \%)$ & $2(66.7 \%)$ \\
\hline $\begin{array}{r}\text { Mandatory research } \\
\text { rotation }\end{array}$ & 2 (5.7\%) & $0(0.0 \%)$ & $2(11.8 \%)$ & $0(0.0 \%)$ & $0(0.0 \%)$ \\
\hline Journal club & $18(51.4 \%)$ & $5(41.7 \%)$ & $11(64.7 \%)$ & $2(66.7 \%)$ & $0(0.0 \%)$ \\
\hline None & $5(14.3 \%)$ & $2(16.7 \%)$ & $2(11.8 \%)$ & $0(0.0 \%)$ & $1(33.3 \%)$ \\
\hline \multicolumn{6}{|c|}{ Mandatory clinical rotations } \\
\hline Administration & $23(65.7 \%)$ & $5(41.7 \%)$ & $14(82.4 \%)$ & $2(66.7 \%)$ & $2(66.7 \%)$ \\
\hline Anesthesiology & $31(88.6 \%)$ & $9(75.0 \%)$ & $16(94.1 \%)$ & $3(100.0 \%)$ & $3(100.0 \%)$ \\
\hline Cardiology & $34(97.1 \%)$ & $12(100.0 \%)$ & $16(94.1 \%)$ & $3(100.0 \%)$ & $3(100.0 \%)$ \\
\hline $\begin{array}{r}\text { ED - Low acuity } \\
\text { ("green" unit) }\end{array}$ & $31(88.6 \%)$ & $10(83.3 \%)$ & $16(94.1 \%)$ & $3(100.0 \%)$ & $2(66.7 \%)$ \\
\hline $\begin{array}{r}\text { ED - Intermediate acuity } \\
\text { ("yellow" unit) }\end{array}$ & $35(100.0 \%)$ & $12(100.0 \%)$ & $17(100.0 \%)$ & $3(100.0 \%)$ & $3(100.0 \%)$ \\
\hline $\begin{array}{r}\text { ED - High acuity } \\
\text { ("red" unit) }\end{array}$ & $35(100.0 \%)$ & $12(100.0 \%)$ & $17(100.0 \%)$ & $3(100.0 \%)$ & $3(100.0 \%)$ \\
\hline $\begin{array}{r}\text { Emergency care units } \\
\text { ("UPA") }\end{array}$ & $25(71.4 \%)$ & $9(75.0 \%)$ & $11(64.7 \%)$ & $3(100.0 \%)$ & $2(66.7 \%)$ \\
\hline $\begin{array}{r}\text { EMS } \\
\text { (pre-hospital) }\end{array}$ & $33(94.3 \%)$ & $10(83.3 \%)$ & 17 (100.0\%) & $3(100.0 \%)$ & $3(100.0 \%)$ \\
\hline ENT & $15(42.9 \%)$ & $3(25.0 \%)$ & $10(58.8 \%)$ & $1(33.3 \%)$ & $1(33.3 \%)$ \\
\hline ICU & $35(100.0 \%)$ & $12(100.0 \%)$ & $17(100.0 \%)$ & $3(100.0 \%)$ & $3(100.0 \%)$ \\
\hline Neurology & 27 (77.1\%) & $10(83.3 \%)$ & $12(70.6 \%)$ & $3(100.0 \%)$ & $2(66.7 \%)$ \\
\hline OBGYN & $35(100.0 \%)$ & $12(100.0 \%)$ & $17(100.0 \%)$ & $3(100.0 \%)$ & $3(100.0 \%)$ \\
\hline Ophthalmology & 17 (48.6\%) & $3(25.0 \%)$ & 9 (52.9\%) & $3(100.0 \%)$ & $2(66.7 \%)$ \\
\hline Orthopedics & $26(74.3 \%)$ & $6(50.0 \%)$ & 15 (88.2\%) & $2(66.7 \%)$ & $3(100.0 \%)$ \\
\hline Palliative care & $21(60.0 \%)$ & $6(50.0 \%)$ & $11(64.7 \%)$ & $3(100.0 \%)$ & 1 (33.3\%) \\
\hline Pediatrics & $33(94.3 \%)$ & $11(91.7 \%)$ & $16(94.1 \%)$ & $3(100.0 \%)$ & $3(100.0 \%)$ \\
\hline POCUS & $24(68.6 \%)$ & $8(66.7 \%)$ & $12(70.6 \%)$ & $2(66.7 \%)$ & $2(66.7 \%)$ \\
\hline Radiology & $24(68.6 \%)$ & $6(50.0 \%)$ & $14(82.4 \%)$ & $2(66.7 \%)$ & $2(66.7 \%)$ \\
\hline Toxicology & $11(31.4 \%)$ & $1(8.3 \%)$ & $6(32.3 \%)$ & $3(100.0 \%)$ & $1(33.3 \%)$ \\
\hline Trauma & $35(100.0 \%)$ & $12(100.0 \%)$ & $17(100.0 \%)$ & $3(100.0 \%)$ & $3(100.0 \%)$ \\
\hline
\end{tabular}

ED, Emergency Department; EMS, emergency medical services (pre-hospital care); ENT, ear nose and throat; OBGYN, obstetrics and gynecology, ICU, intensive care unit; POCUS, point-of-care ultrasound; UPA, Unidade de Pronto Atendimento (equivalent to an emergency care unit in Brazil). 
2020, only 221 physicians have been certified throughout Brazil. ${ }^{9}$ More than half of the program directors reported being board certified, which shows that most residencies are coordinated by EM specialists.

In the curricula evaluation, we found that almost all residency programs offer weekly lectures to residents. Clinical rotations, in contrast, seem to be quite heterogeneous throughout the country, although core rotations highlighted by the International Federation for Emergency Medicine (IFEM) ${ }^{5}$ such as critical care, surgery and subspecialties, pediatrics, prehospital/disaster medicine and ED-based rotations are offered in most programs. Due to the continental dimensions and the great diversity between regions, some level of variation is expected between programs. Interestingly, one area of uniformity is the focus of EM programs in rotations that involve critically ill patients (i.e., all programs require mandatory rotations in ED "red" rooms and ICUs). On the other hand, the exposure to scenarios of less complexity and with patients of less acuity seems to be an area of potential improvement for programs. For example, only $71.4 \%$ of programs rotate in emergency care units (also known as UPAs in Brazil). The UPAs are an essential part of the emergency care system and it is paramount that trained emergency physicians are skilled to work in this setting. Most patients presenting for emergency care will have low-acuity conditions and will be assessed at UPAs, where emergency physicians will often need to make decisions with constrained resources. These decisions will be of great challenge including those involving the difficulties to transfer patients from UPAs to EDs at tertiary hospitals, for example.

Lastly, the high number of programs with three or more affiliated hospitals is likely related to the need of exposing residents to a wide variety of emergencies and to equip them with the knowledge and skills to handle these critical situations under different contexts. However, this data may also reflect the structural distribution of our health care services without EM physicians. In this scenario, it is common to see structural sectorization based on the patient's chief complaint. For example, abdominal pain being seen by a surgeon and chest pain being seen by a cardiologist, creating an important level of "specialist bias". Trainees will often rotate in hospitals that have "specialized" EDs focused on one or two body systems, which could hinder the implementation of the emergency physician mindset who takes care of undifferentiated patients. The fact that residents are frequently staffed and supervised by physicians from other specialties who see only "specific complaints" makes the standardization of EM training more difficult.

As EM evolves in Brazil, more residency programs are expected to emerge along with a growing number of board-certified emergency physicians. Harmonization of training and exchange of experiences between Brazilian regions to create an appropriate standardized curriculum that fits into the Brazilian reality will be important steps to further advance the specialty.

\section{Limitations}

There are several limitations that need to be acknowledged. First, we relied on the survey responses of program directors to establish the characteristics of EM residency programs and no further assessment was performed to confirm the accuracy of information. Second, not all relevant information was asked in our survey (e.g., number of filled slots and demographics of current residents). Other elements important to the current evaluation of residency programs in Brazil remain to be evaluated in future studies. Third, we were not able to contact 4 programs. However, our response rate was very high, and we obtained information on $89.7 \%$ of active programs, yielding a nationally representative sample.

\section{Conclusion}

In this national Brazilian cross-sectional survey, we found a high level of heterogeneity across EM residency programs of different regions including differences in the estimated proportion of faculty with prior EM residency or board certification in EM, number of affiliated hospitals, educational curriculum, research curriculum, and mandatory clinical rotations. In the setting of continuous growth of programs across the country, there is a clear need of standardization of residency programs in Brazil.

\section{References}

1. Nowacki AK, Landes M, Azazh A, Ritchie LMP. A review of published literature on emergency medicine training programs in low- and middleincome countries. Int J Emerg Med. 2013 Dec;6(1):26. DOI: https://doi.org/10.1186/18651380-6-26 
2. Rybarczyk MM, Ludmer N, Broccoli MC, Kivlehan SM, Niescierenko M, Bisanzo M, Checkett KA, Rouhani SA, Tenner AG, Geduld H, Reynolds T. Emergency Medicine Training Programs in Lowand Middle-Income Countries: A Systematic Review. Annals of Global Health. 2020; 86(1): 60, 1-18. DOI: https://doi.org/10.5334/aogh.2681

3. Anderson P, Petrino R, Halpern P, Tintinalli J. The globalization of emergency medicine and its importance for public health. Bulletin of the World Health Organization. 2006; 84(10): 835-9. DOI: https://doi.org/10.2471/BLT.05.028548

4. Holliman CJ, Mulligan TM, Suter RE, Cameron P, Wallis L, Anderson PD, et al. The efficacy and value of emergency medicine: a supportive literature review. Int J Emerg Med. 2011;4(1):44. DOI: https://doi.org/10.1186/1865-1380-4-44

5. International EM Core Curriculum and Education Committee for the International Federation for Emergency Medicine. International Federation for Emergency Medicine model curriculum for emergency medicine specialists. CJEM. 2011; 13(2): 109-21. DOI: https://doi.org/10.2310/8000.2011.110446

6. Henrique Herpich, Lucas Oliveira Junqueira e Silva. Medicina de Emergência no Brasil e no Mundo. In: Medicina de Emergência para Graduação. Rio de Janeiro: Lucas Oliveira Junqueira e Silva, Hélio Penna Guimarães; 2020. p. 3-6.

7. Tannebaum RD, Arnold JL, De Negri Filho A, Spadoni VS. Emergency medicine in southern Brazil. Ann Emerg Med. 2001;37(2):223-228. DOI: https://doi.org/10.1067/mem.2001.112252

8. IBGE | Biblioteca | Detalhes | Sistema de contas nacionais: Brasil 2018 / IBGE, Coordenação de Contas Nacionais [Internet]. [citado 2 de agosto de 2021]. Disponível em: https://biblioteca.ibge.gov.br/index.php/bibliotecacatalogo $?$ view $=$ detalhes $\&$ id $=2101766$

9. ABRAMEDE. Titulados em Medicina de Emergência - AMB. Associação Brasileira de Medicina de Emergência (ABRAMEDE). Accessed on May, 2021. http://abramede.com.br/prova-detitulo-medicina-2019/titulados/.

\section{Article Info}

Received: 02/08/2021

Accepted: 11/09/2021

Funding Sources: This project did not receive any specific grant from funding agencies in the public, commercial, or not-for-profit sectors. Conflict of Interest Disclosure: All authors report no conflict of interest. 